When a parent receives the diagnosis of cancer, he/she starts to have specific concerns about his/her minor children [1-4]. Although some studies start to focus on parenting concerns of parents with cancer, instruments assessing the worries of these parents are not common.

This study assesses the psychometric properties of the Parenting Concerns Questionnaire (PCQ) in a sample of Portuguese parents with cancer.

Participants:

- At this moment, 89 participants (84 women and 5 men) answered the questionnaire but for the validation study, it is needed at least 200 participants [5].

Age: $M=43.89, S D=6.96$ (ranged: $30-71$ ).

Education: 2 attended middle school, 9 high school, and 7 had a bachelor's degree or were college graduates.

Marital status: 70 married or cohabitating with their partners, 12 divorced, 5 single, and 2 widows.

Occupation: 52 employed, 11 unemployed, 3 retired, and 23 on sick leave.

- Number of children: 35 participants had one child, 47 had two children, 5 had three children, and 2 had four children.

\begin{tabular}{c} 
Inclusion \\
criteria: \\
\hline $\begin{array}{c}\text { Adults (males and females) } \\
\text { with at least } 25 \text { years old; }\end{array}$ \\
\hline $\begin{array}{c}\text { Having a diagnosis of } \\
\text { cancer; }\end{array}$ \\
\hline $\begin{array}{c}\text { Be a parent of at least one } \\
\text { minor child; } \\
\text { comple able to understand and } \\
\text { Portuguese. }\end{array}$ \\
\hline
\end{tabular}

Ethical Procedures:

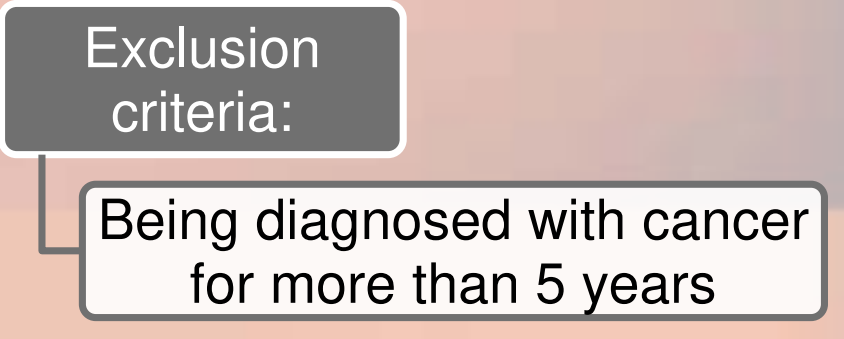

Data Analysis:

o Confirmatory Factor

Analysis;

- Pearson correlation analyses - convergent and concurrent validity.

o Cronbach alpha - test reliability.

○ Approved - Ethical Committee of the FPCEUP;

- Only participants who consented their participation were allowed to proceed and answer the protocol.

Measures:

Parenting Concerns Questionnaire

- 15 items;

- 3 factors related with parenting concerns in parents with cancer;

- Cronbach's a: .79 $-.85$

\section{Parenting Sense of} Competence

- 16 items

- Assess parenting sense of competence

- PT version: Cronbach's a range between .75 and .79
EXPECTED RIESULTS

Table 1: Descriptive Statistics for PCQ 15 Items presented in Muriel and colleagues (2012)

Factor/Variable Mean SD N Factor Loadings

Factor 1: Practical impact of illness on child My own mood, worries or emotions are affecting my children My physical limits or low energy are affecting my children I am not able to spend as much time with $m$ my
My illness is changing my children's routine Changes in my memory or attention are affecting my children Factor 2: Emotional impact of illness on child My children are emotionally upset by my illness
My children are worried that I am going to die My children are worried that I am going to die
My children get upset when we talk about the illn My children get upset when we talk about the illness
My children might be in need of professional mental health care My children might be in need of professional mental health care
My children get confused or upset by what others say about my illness Factor 3: Concerns about coparent My children's other parent would not be able to meet their emotional needs if I die There is no one to take good care of my children if I die My partner is not providing me with enough practical support
My partner is not providing me with enough emotional support My children's other parent would not be a responsible caregiver if I die

\section{CONSIDERATIONS \& CONCLUSION:}

Exploring parenting concerns provides additional relevant information about the experiences and psychological distress of parents with cancer. The PCQ can be an important tool for identifying parents with cancer who might benefit from additional support in parenting by psychological intervention. To our knowledge, this study is a first comprehensive approach to measuring parenting concerns among Portuguese parents with cancer. Parents with diagnosis of cancer are very much concerned about the impact that cancer causes on children, how to communicate the diagnosis and deal with children's negative emotions and reactions [3]. These circumstances can adversely affect both their psychological well-being, and sense of competent mothering [3]. In women with breast cancer, their concerns regarding children were seemingly associated with the demands of their maternal role and with social conceptions about parenting that emphasized the greater importance of their children's needs regardless of the physical and emotional implications of their own BC [3]. So, it is important to have scales, like PCQ, that analyze parenting concerns in parents with cancer, in order to develop intervention for these parents.

References

[1] Rauch, P., \& Muriel, A. C. (2004). The importance of parenting concerns among patients with cancer. Critical Reviews in Oncology/Hematology, 49(1), 37-42. http://doi.org/10.1016/S1040-8428(03)00095-7 | [2] Tavares, R., Brandão, T., \& Matos, P. M. (2017). Mothers with breast cancer: A mixedmethod systematic review on the impact on the parent-child relationship. Psycho-Oncology, 1-9. http://doi.org/10.1002/pon.4451 | [3] Tavares, R., \& Matos, P. M. (2016). Cancro da mama vivido na relação mãe-filhos e na parentalidade. Análise Psicológica, 4(34), 377-390. http://doi.org/10.14417/ap.1223 | [4] Semple, C. J., \& McCance, T. (2010). Parents' experience of cancer who have young children: A literature review. Cancer Nursing, 33(2), 110-118. | [5] Hamilton, J., Gagne, P. E., \& Hancock, G. R. (2003). The effect of sample size on latent growth models. In Paper presented at the Annual meeting of the American Educational Research Association (p. 23). Chicago. 